\title{
Euphorbia antiquorum linn: a comprehensive review of ethnobotany, phytochemistry and pharmacology
}

\begin{abstract}
Medicinal plants are widely used by the traditional practitioners for curing various diseases and ailments in their day-to-day practice. Euphorbia antiquorum Linn is used as a traditional folk medicine in ailments such as inflammation, arthritis, wounds, stomach ache, antioxidant activity, cutaneous infection, diabetes, and as purgative. It looks like a large shrub or small tree. It is one of the largest armed tree Euphorbia's with an average height of $5-7 \mathrm{~m}$, stems are $5-7 \mathrm{~cm}$ thick, green, glabrous, branching from upper parts; upward curving, segmented. The odour of its latex is pungent and lingering. It is commonly found in village shrubberies throughout the tropical and warm temperate regions of India and Ceylon ${ }^{3}$ It is a plant native to India, Sri Lanka and Southeast Asia, has various medicinal value. Phytochemicals studies have shown that the major pharmacologically active constituents are Flavonoid and Triterpenoid. Recent pharmacological study shows that it has antioxidant, immunomodulatory, and anticancer, anti-inflammatory, chemoprotective, antidiabetic and wound healing activity. This review attempts to describe the ethnobotany, pharmacognosy, traditional uses, chemical constituents, and various pharmacologic activities and other aspects of Euphorbia antiquorum linn.
\end{abstract}

Keywords: Euphorbia antiquorum, flavonoid, hepatoproective, triterpinoid, taraxerol
Volume 2 Issue 4 - 2016

\author{
Ajay Kumar, Dharmendra Saikia \\ Department of Molecular Bioprospection, CSIR- Central \\ Institute of Medicinal and Aromatic Plants, India
}

Correspondence: Dharmendra Saikia, Department of Molecular Bioprospection, CSIR- Central Institute of Medicinal and Aromatic Plants, Lucknow 2260I5, Uttar Pradesh, India, Tel 9I-522-27|8650, Email dsaikia.cimap@gmail.com

Received: April 30, 2016 | Published: June 01, 2016

\section{Introduction}

Infectious diseases are major causes of morbidity and mortality in the developing world and accounts for about $50 \%$ of all deaths. Some 5.8 million deaths of infants and children below five years are due to enteric diseases worldwide. ${ }^{1}$ Natural products from plant, animal and minerals have been the basis of the treatment of human diseases. In different parts of the world, there is a rich tradition in the use of herbal medicine for the treatment of many infectious diseases. ${ }^{2,3}$ In developing nations, it is estimated that about $80 \%$ of the population rely mainly on traditional medicine for their primary health care needs. ${ }^{3-5}$ From human civilization till date plants are primary resources of medicines and different civilizations used plants in various ways for medicinal purposes. Traditional systems of medicine are popular to treat different ailments, because these are practised based on theories, experience, beliefs indigenous to different cultures. These systems are based on time testing and expertise evolved on the use of plants as a source of safe medicine. The use of herbal medicine is gaining importance due to the severe side effects associated with allopathic medicines. Herbal medicine is practiced since antiquity as a major source of remedy in traditional system of medicine. The practices continue due to its safer side, medicinal value, biomedical benefits and cultural beliefs in many parts of world. Most of the pathogenic organism developed resistance to the commonly prescribed antibiotics. Bacterial resistance to antibiotics increases mortality, likelihood of hospitalization and the length of stay in the hospital. ${ }^{1}$ Therefore, the demand for new and effective anti-microbial agents with broad-spectrum of activity from natural sources is increasing day by day. ${ }^{6,7}$

Euphorbia antiquorum linn (EA) Euphorbiaceae has several pharmacological applications in folk medicine in curing/managing and preventing a wide range of infectious diseases. $E A$ are found to contain Flavonoids, Polyphenols, Diterpenes and Triterpenes. The plant has a reputation and is used for the diseases like bronchitis, asthma, cutaneous infections neuropathy, deafness and cough. It is also reported to have hepatoprotective, antioxidant, anti-inflammatory, anticancer and antibacterial activity. The present investigation was carried out to compile the medicinal properties of $E A$ and to compare their traditional uses with scientific evidences.

\section{Habitat \& morphology}

EA belongs to the plant family Euphorbiaceae and genus Euphorbia has more than 2000 species and is widely distributed over the world in tropical and temperate regions, ranging from annual weeds to trees. Most originate in Africa, Madagascar, peninsular India and a significant percentage of these are succulent. All contain latex and have a unique flower structure. It is generally found growing up to an altitude of $800 \mathrm{~m}$. It is one of the largest armed tree with an average height of $5-7 \mathrm{~m}$, stems are $5-7 \mathrm{~cm}$ thick, green, glabrous, having branching from upper parts; upward curving and segmented. The odour of its latex is highly pungent and lingering. Ribs are prominent generally three sometimes four to five (4-5), wing like, up to $1-3 \mathrm{~cm}$ wide, $3-5 \mathrm{~mm}$ thick, prominently triangular shaped. Leaves are few, borne on the ridges, succulent, alternate, apically clustered, petiole very short, leaf blade obovate, to oblanceolate to spathulate in shape $2-5(-10) \times 1-2 \mathrm{~cm}$, base attenuate, margin entire, quite insignificant and fall off quickly Apex is rounded or obtuse with pointed projection, base gradually narrowing downward. Leaves are long in the young seedling, margins deeply sinuate. Flowers are cyathia yellowishgreen to pinkish in colour, subterminal, axillary and single or in triads or 3-4 individual cyathia together; peduncles are reddish brown; primary peduncle $1-1.5 \mathrm{~cm}$ long, cyathia peduncle $2-3 \mathrm{~mm}$; all cyathia bisexual; anthers pinkish. Male flower with one stamen, filamentous; female flower lies at the center of the cyathium, protruding beyond the involucre, styles generally three, not joined to each other, each style forking towards the tip. Blooming season of flowers and fruit is throughout the year. They are full of honey that attracted bees. Fruit is capsules, glabrous, obscurely lobed, smooth about $8-10 \mathrm{~mm}$ in dia. and become deep red on maturity year. ${ }^{8,9}$ 


\section{Taxonomy of E. Antiquorum ${ }^{10}$}

Kingdom: Plantae

Phylum: Magnoliophyta

Order: Malpighiales

Class: Angiospermae

Family: Euphorbiaceae

Genus: Euphorbia

Species: E. Antiquorum

Botanical name: Euphorbia antiquorum Linn

\section{Plant parts used}

The latex, leaves, fruit and root are commonly used for the treatment of variety of ailments based on the practices.

\section{Plant description}

It is a succulent plant reached up to height of 8 metre with a diameter of $20-22 \mathrm{~cm}$. The older stems are slender and smooth, with a circular transverse section and having brownish colour of bark while younger and newer branches are green, smooth and distinctly angled, articulate are segmented, shallow to sometime hardly narrowed sinuses between the spine shields. ${ }^{11}$ Stipules converted to spines. Leaves are alternate and flowers surrounded by several staminate flowers. They grow from the axil generally yellow to greenish in colour, solitary and found in dichasia of three sometimes four or five, generally two cm long; basalsupports either a cluster or a solitary flower and peduncle is 4 to $6 \mathrm{~mm}$ long; bracts of branching two $\mathrm{mm}$ long, cyathia is $1 \mathrm{~mm}$ long, sessile in involucre; collection or rosette of bracts are 1.5-2mm long; transversely elliptic, interspersed with erect lobes. Fruits are yellowish to orange in colour, schizocarp, deeply sulcate and sharply keeled. ${ }^{12}$

\section{Chemical constituents}

EAshows the presence of Diterpenes, Triterpenes and Flavonoids with diverse structural classes such as the Jatrophane, Lathyrane, Tigliane, Ingenane, Myrsinol and Ingol types, in which some Diterpenoids showed important biological activities including cytotoxic, antimicrobial, anti-inflammatory, and anti-HIV activities. Isolated compounds from the plant include antiquorin, euphol, antiquolA, euphorbol, isohelinol, camelliol.EA also containsIngenol 3 -angelate is one of the active compounds used as traditional medicines in treating a number of conditions, including warts, corns, waxy growths, skin cancer, asthma, and catarrh. ${ }^{13}$ Latex of the plant EA contains eupha-7, 9(11), 24-trien-3beta-ol (antiquol C), 19(10-->9) abeo-8alpha, 9beta, 10alpha-eupha-5, 24-dien-3betaol (antiquol B), and 24-methyltirucalla-8, 24(24(1))-dien-3beta-ol (euphorbol), lemmaphylla-7, 21-dien-3beta-ol, isohelianol, and camelliol $\mathrm{C}$ showed potent inhibitory effects on Epstein-Barr virus early antigen (EBV-EA) activation induced by the tumor promoter 12-O-tetradecanoylphorbol-13-acetate (TPA). ${ }^{14}$

Three new Triterpenoids, namely friedelane-3 $\beta, 30$-diol diacetate, 30 -acetoxyfriedelan-3 $\beta$-ol and $3 \beta$-acetoxyfriedelan-30-ol were isolated from the stems of $E A .{ }^{15}$

From the latex of $E A$ three new Triterpenes, Euphol 3-O-cinnamate, antiquol A and antiquol B, together with known Triterpenes, Euphol, 24-methylenecycloartanol and cycloeucalenol, (Z)-9-Nonacosene, sitosterol and $p$-acetoxyphenol were also isolated from the latex. ${ }^{16}$
Recent investigations on this plant showed the presence of taraxerol and epi-friedelanol in the stem-bark, friedelan- $3 \beta$-ol and $3 \alpha$ ol, Taraxerol and Taraxerone in the stems, $\beta$-Amyrin, Cycloartenol and Ingenol type Diterpenoids in the latex. Eighteen new Ingol-type Diterpenes, Euphorantins A-R (1-18) are also found in the latex ${ }^{15,16}$ (figure 1-4).

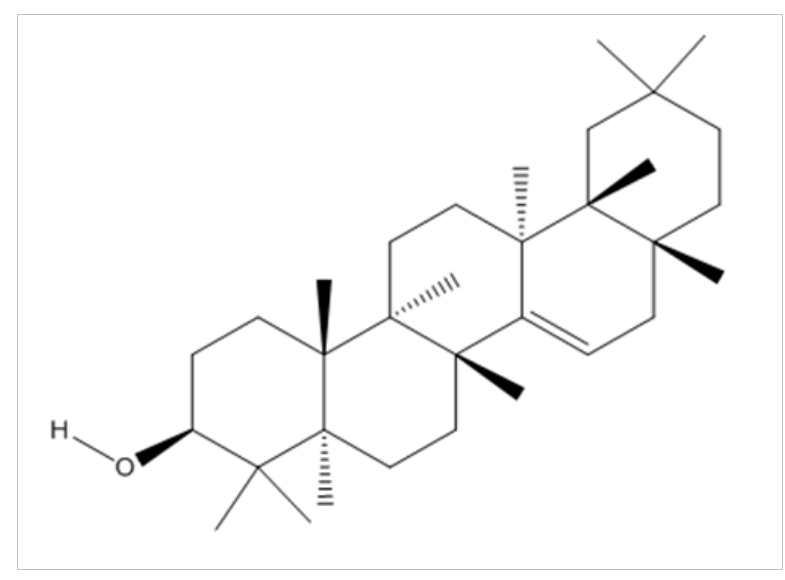

Figure I Taxaxerol.

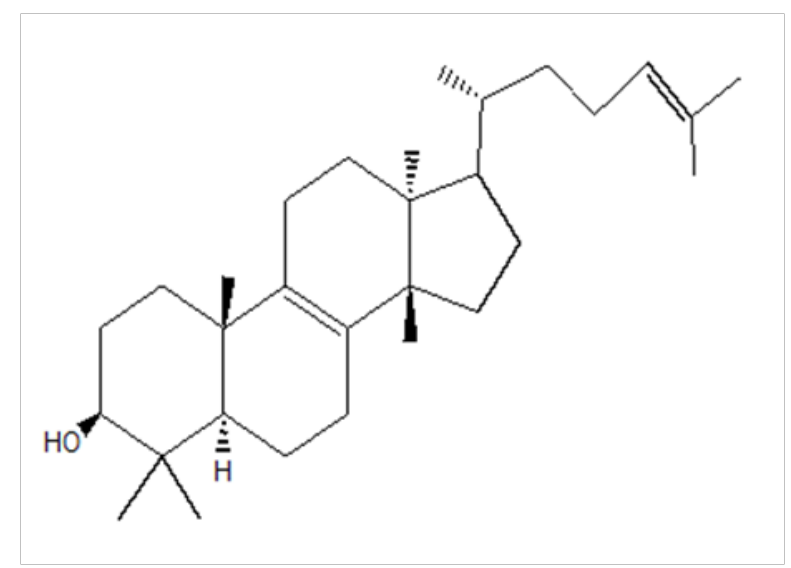

Figure 2 Euphol.<smiles>CC(C)=CCC/C(C)=C/CC/C(C)=C/CC/C=C(\C)CC[C@H]1C(C)=CC[C@H](O)C1(C)C</smiles>

Figure 3 Camelliol $\mathrm{C}$.

\section{Pharmacological activities}

The $E A$ have been associated with a number of pharmacological activities which are enlisted below:

Cytotoxic activity: Cytotoxic assays MTT, SRB and Neutral red were used to analyze the cytotoxic effects of latex in $S$. cerevisiae cells. $S$. 
cerevisiae cells were used as a model organism for normal cells. The latex extract was added in 5 different concentrations namely 10, 20, $30,40,50 \mu \mathrm{g}$. The results revealed that the latex at lower concentration showed better cell survival compared to higher concentration. The results also suggest its use in combination therapy along with chemotherapy to fight cancer. ${ }^{17}$

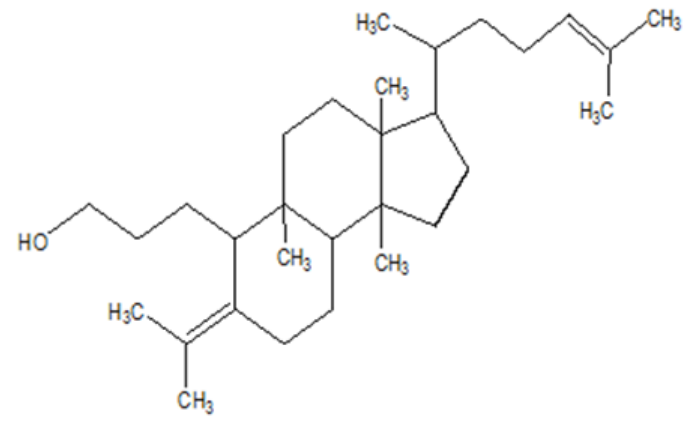

Figure 4 Isohelianol.

Hepatoprotective and antioxidant activity: Aqueous extract of the leaf has been reported to have hepatoprotective and antioxidant activity. $E A$ extract exhibit significant antioxidant activity (at $20 \mu \mathrm{g}$, $40 \mu \mathrm{g}, 60 \mu \mathrm{g}, 80 \mu \mathrm{g}$ and $100 \mu \mathrm{g} / \mathrm{ml}$ in vitro) as evidenced by its reducing ability, hydroxyl and superoxide anion radical scavenging activities. The in vitro data showed significant dose dependent hepato-protection (at $125 \mathrm{mg} / \mathrm{kg}$ and $250 \mathrm{mg} / \mathrm{kg}$ dose) by altering the activity of bilirubin, cholesterol, serum enzymes, triglycerides and lipid peroxidation while it significantly increased the glutathione levels of tissue in a dose dependant manner. Previous work reported the hepatoprotective and antioxidant activities of $E A$ extract is significantly comparable to standard Silymarin and sodium metabisulphite and claims it may be used for the treatment of jaundice. ${ }^{18}$

Insecticidal activity: Six species of insect pests were used for bioassays. Bioassays with 10\% latex solvent extracts gave 100\% mortalities except for the extract with distilled water $(0 \%)$. Since the mortalities observed may be due to leaf-scorching/white mesh formation rather than direct insecticidal effect of the tested compounds, the latex extracts were diluted to $0.1 \%$ with relevant solvents and the bioassays were repeated. White mesh formation was still evident with dichloromethane, n-hexane and petroleum ether extracts, the xylene-latex extract and the methanol-latex extract gave the highest mortalities. The observed $\mathrm{LC}^{50}$ of $M$. Persicae with latex extract $(0.012 \%)$ was, however, greater than that with Azadirachta seed oil $(0.0024 \%) E A$ latex extract was not effective against insects with thick cuticle covers. Although soft-bodied natural enemies like spiders are susceptible to the latex of $E A$, most common and important natural enemies like ladybird beetles are highly resistant. ${ }^{19}$

Anti-hyperglycaemic activity: Alcoholic and aqueous extract of $E A$ root has been reported to show anti-hyperglycaemic effect in streptozotocin-nicotinamide induced and fructose induced diabetic rats. Alloxan induced diabetic rats were treated with $200 \mathrm{mg} / \mathrm{kg}$ of Ethanol, Petroleum ether and Aqueous extracts of EA. The blood glucose level was estimated after $8 \mathrm{hrs}$ of drug treatment. The ethanol extract exhibited a drastic reduction in blood sugar level after 1 hour of post treatment $(30.11 \%)$. This effect was significant compared to standard drug Glibenclamide (23.36\%). Glide algorithm was used to dock the terpenoids Antiquol A, Antiquol B, and Antiquol C against the aldose reductase in standard precision mode. The obtained results showed that all the extracts of $E A$, has hypoglycemic effect, the ethanol extract $(69 \%)$ had more hypoglycemic effect which is comparable with standard drug Glibenclamide (80\%). Molecular docking study reveals that Antiquol A was found to be one of the best aldose reductase inhibitor with glide score $-9.07 \mathrm{kcal} / \mathrm{mol}$. Result concluded that the EA has anti-diabetic as well as aldose reductase inhibitory effect. ${ }^{20,21}$

\section{Cancer}

Latex of EA has inhibitory effects on several different cancer cell lines. EA induced apoptosis, which was characterized by morphological change, DNA fragmentation, increased sub-G1 population, and alterations in levels of apoptosis associated proteins. Treatment with $E A$ increase cell death and expression levels of caspase-8, -9 , and -3. EA suppressed expression of Bcl-2, increased bax, and reduced cleavage of Bid and the translocation of $\mathrm{t}$-Bid to the mitochondria and the release of cytochrome $c$ from mitochondria. EA caused a loss of mitochondrial membrane potential and an increase in cellular reactive oxygen species (ROS). EA -induced ROS formation was suppressed by cyclosporine or allopurinol (an effective scavenger of ROS). EA also increased expression of Fas, FasL, and c-Jun N-terminal kinase (JNK), p38, and mitogen-activated protein kinase (MAPK) and decreased expression of extracellular signal-regulated kinase (ERK).Co-treatment with the JNK inhibitor SP600125 inhibited EAinduced apoptosis and the activation of caspase $-8,-9$, and -3 . It could be hypothesised that $E A$ causes cell death via apoptotic pathways in human cervical adenocarcinoma HeLa cells. ${ }^{22}$

\section{Anti-inflammatory and anti-arthritic activities}

The anti-inflammatory and anti-arthritic potential has been associated with aqueous (AEA) and alcoholic (EEA) extracts of $E A$. The effect of the extracts was evaluated against acute inflammation using carrageenan induced rat paw edema and chronic inflammation using cotton pellet induced granuloma in rats and complete Freund's adjuvant (CFA) induced arthritis in rats. In acute oral toxicity study, EEA and AEA did not show any toxicity and mortality up to the dose of $2 \mathrm{~g} / \mathrm{kg}$. AEA and EEA at 200 and $400 \mathrm{mg} / \mathrm{kg}$, po produced significant inhibition of carrageenan induced rat paw edema. AEA and EEA at $400 \mathrm{mg} / \mathrm{kg}$, po showed significant inhibition of cotton pellet induced granuloma formation in rats. AEA $400 \mathrm{mg} / \mathrm{kg}$, po effectively prevented the primary lesions and EEA $400 \mathrm{mg} / \mathrm{kg}$, po effectively prevented both primary and secondary lesions of CFA induced arthritis in rats. The results revealed that the Triterpenoids present in both the extracts of $E A$ might be responsible for anti-inflammatory and anti-arthritic effects. $^{23}$

\section{Antibacterial activity}

In the study the disc diffusion method was used to determine the antibacterial activity of EA latex extract against Escherichia coli, Staphylococcus aureus, Proteus vulgaris, Bacillus subtilis, Micrococcus luteus and Vibrio parahaemolyticus. The antibacterial sensitivity test indicated that the methanolic extract inhibited the growth of the bacterial isolates at varying extents. ${ }^{24}$

\section{Traditional uses of Euphorbia Antiquorum}

The literature indicated various traditional uses of Euphorbia antiquorum which are enlisted below: Fresh milky juice or gum used as aphrodisiac, conjunctivitis, cough, cutaneous infection, deafness, dropsy, emetic, fistula wounds, in jaundice leprosy, neuropathy, palsy, pain of gout, rheumatism, toothache, gonorrhoea, purgative, joints swelling, inveterate ulcer, enlargement of spleen, in snake 
bite, anti-microbial, nervous diseases, warts and corneal opacity of cattle. Stem of plant is used in worms, ulcers, wound healing, gout, hyperglycaemic, joint pains, cancer, phthisis, liver cancer, colon cancer cytotoxicity, skin sores and scabies. Whole part of the plant is used as antitussive and anti-cancer. ${ }^{1,25}$

\section{Conclusion}

Conventional treatment modalities are hindered by adverse effects and produce only a partial remission. Due to the drawbacks associated with the conventional therapy, there has been renewed interest in other alternative therapies with medicinal plants, which may have comparable efficacy to prescription medications while lacking their serious side effects. Phytochemical and pharmacological investigations carried out in the plant reveals its multidisciplinary usage. It is very essential to have a proper documentation of medicinal plants and to know their potential for the improvement of health and hygiene through an eco-friendly system. A detailed and systematic study is required for identification, cataloguing and meaningful way for the promotion of the traditional knowledge of the herbal medicinal plants. The present review reveals that the $E A$ is used in treating various ailments and having potential as medicinal value.

\section{Acknowledgments}

None.

\section{Conflicts of interest}

Authors declare that there is no conflict of interest.

\section{References}

1. El Mahmood MA. Antibacterial activity of crude extracts of Euphorbia hirta against some bacteria associated with enteric infections. Journal of Medicinal Plants Research. 2009;3(7):498-505.

2. Brantner A, Grein E. Antibacterial activity of plant extract used externally in traditional medicine. J Ethanopharm. 1994;44(1):35-40.

3. Kumar OA, Naidu LM, Raja Rao KG. Antibacterial evaluation of snake weed (Euphorbia hirta L). Journal of Phytology. 2010;2(3):8-12.

4. Matu EN, Staden JV. Antibacterial and anti-inflammatory activities of some plants used for medicinal purposes in Kenya. $J$ Ethanopharm. 2003;87(1):35-41.

5. Dash BK, Faruquee HM, Biswas SK, et al. Antibacterial and Antifungal Activities of Several Extracts of Centellaasiatica L. against Some Human Pathogenic Microbes. Life Sciences and Medicine Research; 2011. 1-5 p.

6. Mamun RANM, Islam MR, Dash BK. In vitro Antibacterial Effect of Bushy Matgrass (Lippiaalba Mill) Extracts. Research Journal of Medicinal Plants. 2012;6(4):334-340.

7. Sen MK, Faruquee HM, Mamun RANM. Antibacterial Activity of Cissus quadrangularis Stem- A Preliminary In vitro Effort to Develop Antibiotic. LAP-LAMBERT Academic Publisher: Germany; 2012. 24-27 p.
8. Deka P, Vodhdal KK. Ethoidrical uses of Euphorbia antiquorum and Euphorbia Ligulariaroxbinassam. Indian Journal of Traditional Knowledge. 2008;7(3):466-468.

9. Euphorbia antiquorum

10. https://inpn.mnhn.fr/espece/cd_nom/446636/tab/taxo?lg=en

11. Kirtikar KR, Basu BD. Indian medicinal plants. India; 1975. 2204-2216 p.

12. Warrier PK. Indian Medicinal Plants: A Compendium of 500 Species. Orient Blackswan: Hyderabad, India; 1993. 388 p.

13. Noemi K, Daniel JL, Attila $\mathrm{T}$, et al. Characterization of the Interaction of Ingenol 3-Angelate with Protein Kinase C. Cancer Res. 2004;64(9):3243-3255.

14. Akihisa T, Wijeratne K, Tokuda H, et al. Eupha- 7,9(11),24-trien-3b-ol ('Antiquol C) and other triterpenes from Euphorbia antiquorumlatex and their inhibitory effects on Epstein- Barr virus activation. J Nat Prod. 2002;65(2):158-162.

15. Anjaneyulu V, Ravi K. Terpenoids from Euphorbia antiquorum. Phytochemistry. 1989;28(6):1695-1697.

16. Gewali MB, Hattori M, Tezuka Y, et al. Constituents of the latex of Euphorbia antiquorum. Phytochemistry. 1990;29(5):1625-1628.

17. Sumathi S, Malathy N, Dharani B, et al. Cytotoxic Studies of Latex of Euphorbia antiquorum In-vitro Models. Journal of Medicinal Plants Research. 2011;5(19):4715-4720.

18. Jyothi TM, Prabhu K, Jayachandran E, et al. Hepatoprotective and antioxidant activity of Euphorbia antiquorum. Pharmacognosy Magazine. 2008;4(13):127-133.

19. Silva DW, Manuweera G, Karunaratne S. Insecticidal Activity of Euphorbia antiquorum L. Latex and Its Preliminary Chemical Analysis. Journal of the National Science Foundation of Sri Lanka. 2008;36(1):15-23.

20. Amutha P, Kumar N, Jayakumar P, et al. A study of Anti-hyperglycemic and insilico Aldose reductase inhibitory effect of terpenoids of Euphorbia antiquorum Linn. In alloxan induced diabetic rats. Indian Journal of Drugs and Diseases. 2012;1(7):173-169.

21. Madhavan V, Murali A, Lalitha DS, et al. Studies on anti-hyperglycemic effect of Euphorbia antiquorum L. root in diabetic rats. $J$ Intercult Ethnopharmacol. 2015;4(4):308-313.

22. Wen TH, Hui YL, Jou HC, et al. Latex of Euphorbia Antiquorum Induces Apoptosis in Human Cervical Cancer Cells via c-Jun N-terminal Kinase Activation and Reactive Oxygen Species Production. Nutr Cancer. 2012;63(8):1339-1347.

23. Parveen AB, Vikas G, Ranjit S, et al. Pharmacological potential of medicinal plant used in treatment of gout. Drug Invention Today. 2010;2(10):433-435.

24. Benrit VJ, Das SSM, Vareethiah K. Antibacterial activity of Euphorbia antiquorum Linn. Plant latex. Journal of Basic and Applied Biology. 2012;6(2-4):36-39.

25. Shivani R, Ramandeep S, Preeti T, et al. Wound healing Agents from Medicinal Plants: A Review. Asian Pacific Journal of Tropical Biomed. 2012;2(3):1910-1917. 